\title{
Notes on Books
}

Owing to the death of Professor Thomson, the onus of revision has devolved on Mr Miles, to whom great credit is due for having brought the work well abreast of the recent advances in surgery. The manual which has hitherto proved so valuable both to undergraduates and graduates, will, the reviewer is confident, continue to have a wellmerited popularity. The third volume is now in the press.

\section{Chemical Pathology: Being a Discussion of General Pathology from the} Standpoint of the Chemical Processes involved. By H. Gideon Wells, Ph.D., M.D. Fifth Edition. Pp. 790. London and Philadelphia : W. B. Saunders Co. Ltd. I925. Price 4 os.

This is the most useful and exhaustive work on the chemistry of pathological conditions published in the English language. It is invaluable alike to the physician, the pathologist and the biochemist, and has justly come to be regarded as the standard work on the subject. The book is the more valuable in that chemical changes are dealt with from the point of view of the physician and pathologist rather than, as is frequently the case, pathology and medicine from the point of view of the chemist. The bibliography, though very extensive, does not profess to be complete, but this possible defect is amply compensated for by the fact that the author specially indicates those papers which themselves contain extensive reviews of the literature upon particular points. The labour involved in keeping such a book up-to-date must be immense, and Dr Wells is to be congratulated for the careful and systematic way in which this has been done.

\section{NOTES ON BOOKS}

F.R.C. Gastric Function in Health and Disease, by J. A. Ryle, M.D., given at (Milford, 8s. 6d.), is a reprint of the Goulstonian Lectures results the Royal College of Physicians in 1925. It contains the as a comprehensiver's clinical and experimental observations as well with the test meals of digestion the causes of pain and other symptoms, and the processes Astion as modified by gastro-jejunostomy.

F.R.C.P. Ana and its Radical Treatment, by James Adam, M.A., M.D., treat asthe. \&. (Glas.) (Kimpton, ros. 6d.). To those who have to with asthmatics, equally to those who investigate phenomena associated interesting, bes, the second edition of Dr Adam's book will prove experience fromful, and maybe provocative. The wealth of clinical 


\section{Notes on Books}

asthma to an error in protein metabolism closely connected with excess of carbohydrates in the diet. We note that there is little experimental evidence to support this view and hope that this point will be remedied, together with the omission of a description of the cutaneous tests, which even Dr Adam employs in certain cases.

Rational Gland Therapy for Women, by J. Wanless Dickson (Lewis, 4s. 6d.), contains much that is helpful. It is based on a clinical investigation of various gynæcological disorders having a presumable endocrinological basis. Recent research, however, has demonstrated the inefficacy of the majority of organic extracts given by mouth and thus throws open to question the validity of certain conclusions offered by the author.

The aim of The Therapy of Puerperal Fever, by Robert Koehler, English Edition, prepared by H. Ehrenfest (Kimpton, I8s.), is to assess at their true value the increasingly numerous therapeutic agents available for the treatment of puerperal sepsis. The work, which is based on the author's exceedingly large personal experience, consists of two parts, the first deals briefly with prophylaxis, in the second various therapeutic measures are critically discussed. The author is definitely conservative as regards instrumentation of the septic puerperal uterus. He condemns wholeheartedly ligation of veins. He has found the intravenous use of sera, foreign proteins and antiseptics disappointing, and is lukewarm in his attitude towards vaccine therapy. General stimulation, blood transfusion, and fresh air are the most efficient remedies at present at our disposal.

Uterine Hamorrhage, by Samuel J. Cameron and John Hewitt (Arnold, 8s. 6d.). It might seem extravagant that a single symptom such as uterine hæmorrhage should form the sole theme of a book, but this is justified by the authors on the ground that uterine hæmorrhage is the symptom above all others which should never be disregarded, as it so frequently indicates some serious gynæcological lesion or gross abnormality of pregnancy. The obstetrical section will appeal to the practitioner, as it is eminently practical and the methods of treatment described are, on the whole, the result of the authors' experience. The chapter on ante-partum hæmorrhage deserves special mention. The gynæcological section will appeal more to the specialist than to the general practitioner. The section on cancer of the cervix is excellent.

In Gynacologic Urology, by L. L. Fulkerson, A.B., M.D., F.A.C.S. (Heinemann, $27 \mathrm{~s}$. 6d.), the author presents briefly and with moderate success the subject of urology as seen in the female. On the whole, the volume covers the ground satisfactorily and should be of use to the gynæcologist who has to deal with the many complications met with in the female urological tract. 